OPEN ACCESS

Edited by:

Ying Guan,

Institute of Vertebrate Paleontology and Paleoanthropology (CAS), China

Reviewed by:

Xinying Zhou,

Institute of Vertebrate Paleontology and Paleoanthropology (CAS), China

Li Wu,

Anhui Normal University, China

*Correspondence:

Keyang $\mathrm{He}$

hekeyang1991@163.com

Houyuan Lu

houyuan/u@mail.iggcas.ac.cn

Specialty section:

This article was submitted to Quaternary Science, Geomorphology and Paleoenvironment, a section of the journal

Frontiers in Earth Science

Received: 06 January 2022 Accepted: 08 February 2022 Published: 24 February 2022

Citation: He K, Lu H, Sun G, Wang Y, Zheng Y, Zheng H, Lei S, Li Y and Zhang J (2022)

Dynamic Interaction Between Deforestation and Rice Cultivation During the Holocene in the Lower Yangtze River, China.

Front. Earth Sci. 10:849501. doi: 10.3389/feart.2022.849501

\section{Dynamic Interaction Between Deforestation and Rice Cultivation During the Holocene in the Lower Yangtze River, China}

\author{
Keyang $\mathrm{He}^{1 *}$, Houyuan $\mathrm{Lu}^{1,2,3 *}$, Guoping Sun ${ }^{4}$, Yonglei Wang ${ }^{4}$, Yunfei Zheng ${ }^{4}$, \\ Hongbo Zheng ${ }^{5}$, Shao Lei ${ }^{6}$, Yongning $L^{6}{ }^{6}$ and Jianping Zhang ${ }^{1,2}$
}

${ }^{1}$ Key Laboratory of Cenozoic Geology and Environment, Institute of Geology and Geophysics, Chinese Academy of Sciences, Beijing, China, ${ }^{2}$ Innovation Academy for Earth Science, Chinese Academy of Sciences, Beijing, China, ${ }^{3}$ College of Earth and Planetary Sciences, University of Chinese Academy of Sciences, Beijing, China, ${ }^{4}$ Zhejiang Provincial Institute of Cultural Relics and Archaeology, Hangzhou, China, ${ }^{5}$ Earth System Science Research Center, Yunnan University, Kunming, China, ${ }^{6}$ Ningbo Municipal Institute of Cultural Relics and Archaeology, Ningbo, China

Human activity has transformed the Earth's landscapes pervasively for thousands of years, and the most important anthropogenic alteration was the clearing of forests and the establishment of agriculture. As a center of rice domestication and early population growth, the lower Yangtze River has been extensively transformed in the Holocene. However, the timing, extent, and process of deforestation and its relationship with the intensification of rice cultivation remain controversial. Here, four representative archaeological sites ranging from 8,100 to 4,300 cal a BP, that is, Jingtoushan, Hemudu, Yushan, and Xiawangdu sites, were selected for detailed palynological analysis, and evidence of anthropogenic deforestation and subsistence strategy were also synthesized to investigate dynamic human-forest interaction. Although natural vegetation had already been altered at the Jingtoushan site around 8,000 cal a BP, it was more likely to be the management of acorns by limiting burning to open habitats and increasing yield. As the subsistence shifted from acorn exploitation toward rice cultivation after 6,000 cal a BP, real deforestation for agriculture may occur at the Yushan and Xiawangdu sites due to conflict on labor input and land use. However, these deforestations were just confined to the archaeological sites at local scale, and no consistent vegetation change occurred at regional scales induced by human activities until the last 3,000 years.

Keywords: deforestation, rice cultivation, Jingtoushan, palynological analysis, lower Yangtze River

\section{INTRODUCTION}

Human activity has altered the Earth's system pervasively by transforming landscapes, changing vegetational biodiversity, and altering atmospheric composition (Olofsson and Hickler, 2008; Ruddiman et al., 2015; Mottl et al., 2021). Global land-use modeling and ArchaeoGLOBE synthesis revealed that agriculture and pastoralism had become extensive since $6,000 \mathrm{cal}$ a $\mathrm{BP}$, and largely transformed the planet by 3,000 cal a BP (Kaplan et al., 2011; Stephens et al., 2019). In addition, early anthropogenic hypotheses attributed the anomalous increase in atmospheric $\mathrm{CO}_{2}$ after 7,000 cal a BP and $\mathrm{CH}_{4}$ after 5,000 cal a BP to prehistoric deforestation and wet-rice farming, respectively (Ruddiman, 2003; Ruddiman et al., 2016). As the most important anthropogenic 


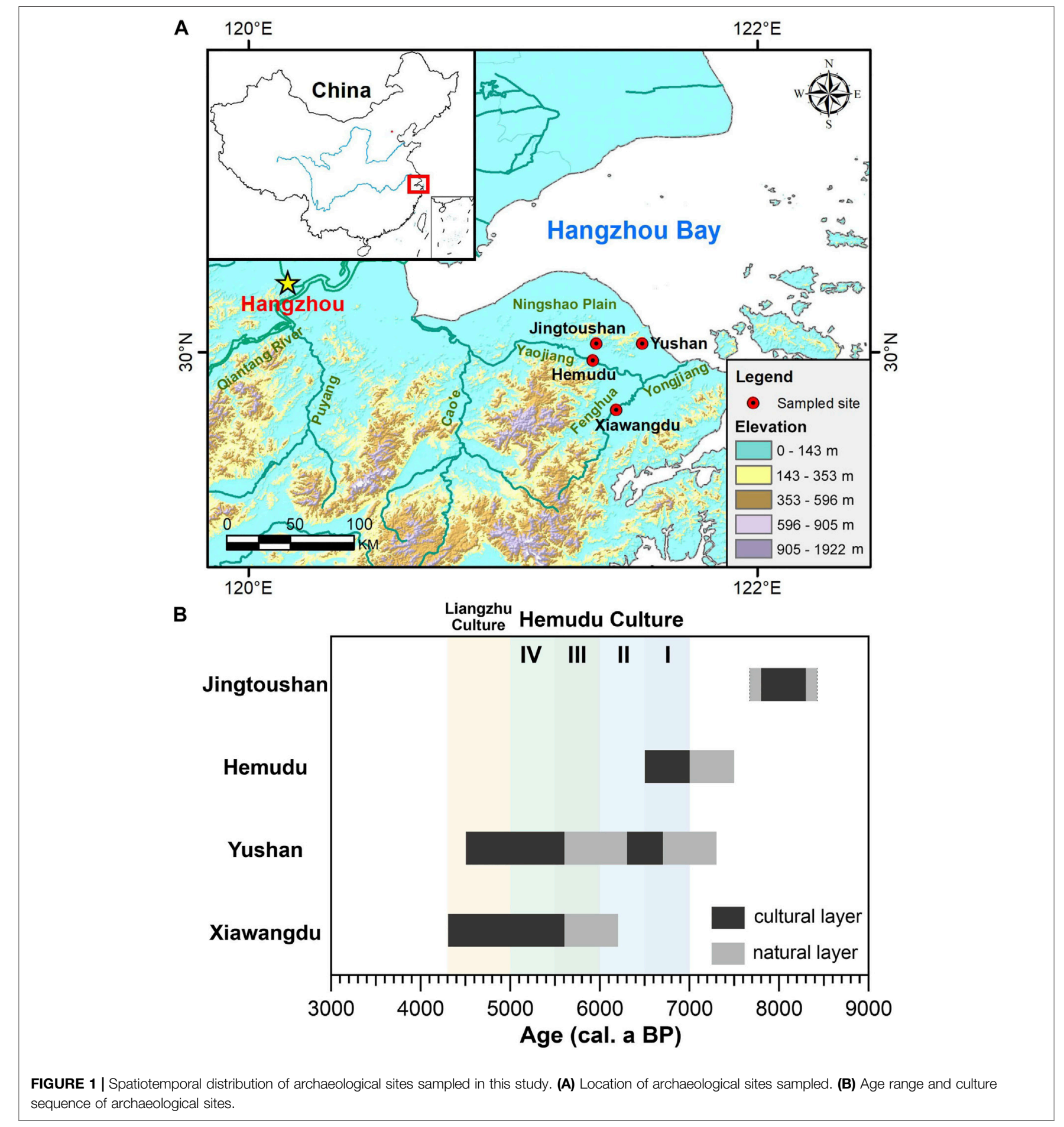

alteration of the natural environment, deforestation and agriculture have been intensively debated by scientists across disciplines (Kaplan et al., 2009; Li et al., 2009).

Although China was widely recognized as a center of rice domestication and early population growth (Lu et al., 2002; Hosner et al., 2016; Zuo et al., 2017), the timing and extent of anthropogenic deforestation were still in dispute. Palynological records indicate human activities have altered the natural vegetated landscapes by deforestation in southern China since $6,000 \mathrm{cal}$ a BP and resulted in a $37 \%$ decrease in forest cover in the Yangtze River (Ren, 2006; Cheng et al., 2018). In contrast, synthesis of pollen records in eastern China suggests the effects of human disturbance on vegetation may only occur at some local sites early in the Holocene and have only become an increasingly important factor during the last 2000 years (Liu and Qiu, 1994; Zhao et al., 2009). However, most of these studies have 
TABLE 1 | A summary of $A M S^{14} \mathrm{C}$ ages from the archaeological sites sampled.

\begin{tabular}{|c|c|c|c|c|c|c|}
\hline Site & Depth (cm) & Lab code & Material & $\begin{array}{c}{ }^{14} \mathrm{C} \text { age } \\
(\text { a BP, } \pm 1 \sigma)\end{array}$ & $\begin{array}{c}\text { Calibrated age } \\
\text { (a BP, 2б) }\end{array}$ & Reference \\
\hline Jingtoushan & 812 & Beta412378 & Plant $^{a}$ & $7,150 \pm 30$ & $8,019-7,877$ & This study \\
\hline Jingtoushan & 846 & Beta412377 & Charcoal & $7,180 \pm 30$ & $8,025-7,939$ & This study \\
\hline Jingtoushan & 866 & Beta412376 & Charcoal & $7,210 \pm 30$ & $8,165-7,942$ & This study \\
\hline Jingtoushan & 886 & Beta412375 & Plant $^{a}$ & $7,150 \pm 30$ & $8,019-7,877$ & This study \\
\hline Jingtoushan & 906 & Beta412374 & Charcoal & $7,180 \pm 30$ & 8,025-7,939 & This study \\
\hline Jingtoushan & 857 & PLD26540 & Fruit & $7,130 \pm 25$ & $8,011-7,874$ & This study \\
\hline Jingtoushan & 870 & PLD26541 & Seed & $7,130 \pm 25$ & $8,011-7,874$ & This study \\
\hline Jingtoushan & 887 & PLD26542 & Wood & $7,215 \pm 25$ & $8,165-7,958$ & This study \\
\hline Jingtoushan & $820-870$ & BA140472 & Acorn & $6,820 \pm 30$ & $7,695-7,584$ & This study \\
\hline Jingtoushan & 870-920 & BA140473 & Charcoal & $6,995 \pm 30$ & $7,932-7,735$ & This study \\
\hline Jingtoushan & 870-920 & BA140474 & Acorn & $7,060 \pm 30$ & $7,961-7,799$ & This study \\
\hline Hemudu & 172 & UGa32508 & Charcoal & $5,850 \pm 35$ & $6,747-6,557$ & He et al. (2020b) \\
\hline Hemudu & 227 & Beta456259 & Wood & $6,070 \pm 30$ & $7,150-6,798$ & He et al. (2020b) \\
\hline Hemudu & 260 & UGa32509 & Charcoal & $6,190 \pm 30$ & $7,235-6,988$ & He et al. (2020b) \\
\hline Hemudu & 275 & Beta456260 & Wood & $6,010 \pm 30$ & $6,943-6,749$ & He et al. (2020b) \\
\hline Hemudu & 335 & UGa32510 & Charcoal & $6,200 \pm 30$ & $7,241-6,995$ & He et al. (2020b) \\
\hline Hemudu & 484 & UGa32511 & Charcoal & $6,520 \pm 30$ & $7,506-7,330$ & He et al. (2020b) \\
\hline Yushan & $65-70$ & BA151803 & Plant $^{\mathrm{a}}$ & $4,040 \pm 30$ & $4,612-4,418$ & He et al. (2018) \\
\hline Yushan & $100-105$ & BA151804 & Seed & $4,365 \pm 25$ & $5,030-4,856$ & He et al. (2018) \\
\hline Yushan & $125-130$ & BA151805 & Seed & $4,300 \pm 25$ & $4,959-4,830$ & He et al. (2018) \\
\hline Yushan & $150-155$ & BA151806 & Seed & $4,525 \pm 25$ & $5,310-5,051$ & He et al. (2018) \\
\hline Yushan & $180-185$ & BA151807 & Seed & $4,785 \pm 25$ & $5,585-5,475$ & He et al. (2018) \\
\hline Yushan & $215-220$ & BA151808 & Seed & $5,495 \pm 25$ & $6,391-6,211$ & He et al. (2018) \\
\hline Yushan & $230-235$ & BA151809 & Seed & $5,665 \pm 25$ & $6,500-6,352$ & He et al. (2018) \\
\hline Yushan & $245-250$ & BA151810 & Seed & $5,860 \pm 25$ & $6,745-6,568$ & He et al. (2018) \\
\hline Yushan & 260-265 & BA151811 & Seed & $6,225 \pm 25$ & $7,250-7,010$ & He et al. (2018) \\
\hline Xiawangdu & $40-35$ & UGa32514 & Charcoal & $4,420 \pm 30$ & $5,271-4,870$ & He et al. (2020a) \\
\hline Xiawangdu & $60-55$ & UGa38688 & Rice seed & $4,460 \pm 20$ & $5,281-4,975$ & He et al. (2020a) \\
\hline Xiawangdu & $80-75$ & UGa32515 & Rice seed & $4,570 \pm 30$ & $5,442-5,053$ & He et al. (2020a) \\
\hline Xiawangdu & $115-110$ & UGa38687 & Rice seed & $4,650 \pm 20$ & $5,463-5,315$ & He et al. (2020a) \\
\hline Xiawangdu & $140-135$ & UGa32516 & Rice seed & $5,100 \pm 30$ & $5,920-5,747$ & He et al. (2020a) \\
\hline Xiawangdu & $150-145$ & UGa38686 & Rice seed & $4,760 \pm 20$ & $5,583-5,467$ & He et al. (2020a) \\
\hline Xiawangdu & $160-155$ & UGa32517 & Rice seed & $4,850 \pm 30$ & $5,654-5,479$ & He et al. (2020a) \\
\hline Xiawangdu & $175-165$ & UGa38685 & Rice seed & $5,070 \pm 20$ & $5,902-5,746$ & He et al. (2020a) \\
\hline
\end{tabular}

${ }^{a}$ Plant indicates fragments of unidentifiable plant that has not been fully charred.

been conducted on natural sediments and have exhibited indirect signals of human activities, lacking archaeological evidence.

In the lower Yangtze River, pollen and charcoal data from the Kuahuqiao site demonstrated that alder-dominated wetland scrub or oak-pine-dominated forests had been cleared using fire by early rice-cultivators after $7,700 \mathrm{cal}$ a BP (Zong et al., 2007; Innes et al., 2009; Shu et al., 2012). Nevertheless, charcoal analysis from cores near the Kuahuqiao site suggested that human-induced fires were restricted to a small geographic area with no constant large-scale slash-and-burn farming activities (Hu et al., 2020). Pollen data from paddy fields at the Tianluoshan site also suggested no evidence of slash-and-burn agriculture from 7,000 to 4,200 cal a BP (Li et al., 2012). Black carbon analysis of paddy soils from the Chuodun site further demonstrated that the fire was applied to burn crop residue rather than natural vegetation (Hu et al., 2013). Thus, whether the deforestation and slash-and-burn agriculture were adopted in the lower Yangtze River remains controversial.

To investigate the timing, extent, and process of deforestation in the lower Yangtze River and its relationship with the intensification of rice cultivation, four representative archaeological sites (i.e., Jingtoushan, Hemudu, Yushan, and Xiawangdu) (Figure 1A) were selected for detailed palynological analysis in this study. Furthermore, evidence of deforestation induced by human activities and the transition of subsistence strategy in this region were also synthesized to offer insight into the dynamic interaction between deforestation and rice cultivation in the Holocene.

\section{MATERIALS AND METHODS}

\section{Study Site and Sample Collection}

The four archaeological sites are located on the Ningshao Plain on the southern shore of Hangzhou Bay in eastern China (Figure 1A). The sequence of Neolithic cultures mainly consisted of the Hemudu Culture $(7,000-5,000 \mathrm{cal}$ a BP), which is generally subdivided into four periods at approximately 500-year intervals (Wang, 2000), and the Liangzhu Culture $(5,000-4,300 \mathrm{cal}$ a BP) (Figure 1B). The mean annual precipitation and temperature in this region are c. $1000-1,400 \mathrm{~mm}$ and $\mathrm{c} .15-16^{\circ} \mathrm{C}$, respectively. Regional 


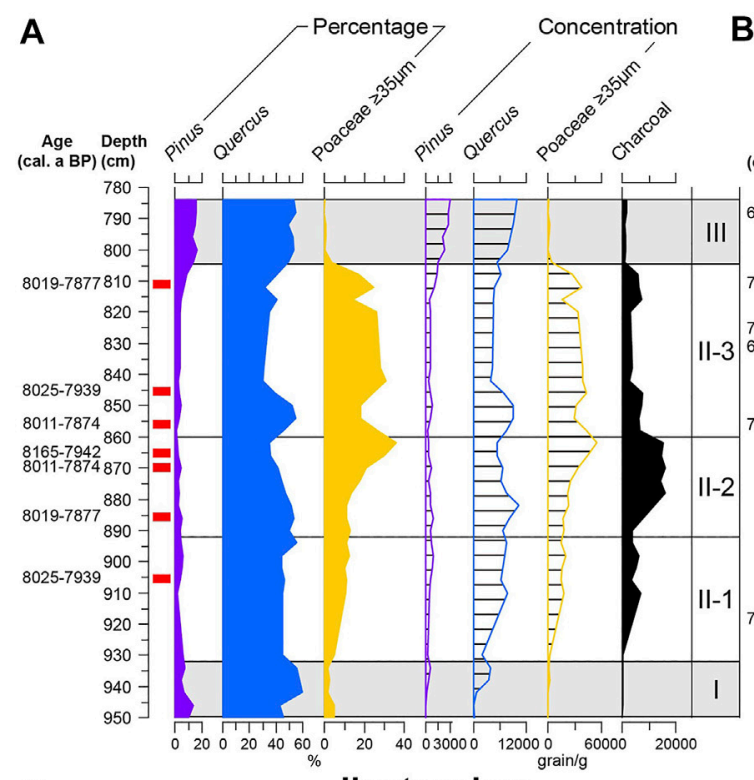

C

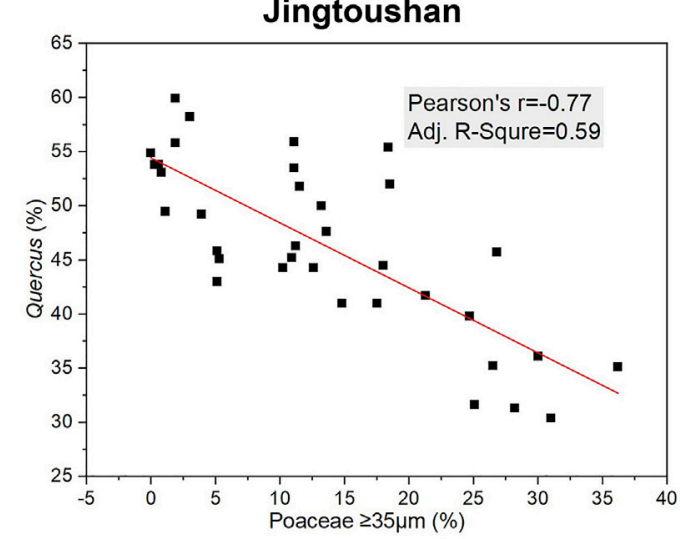

Jingtoushan
B

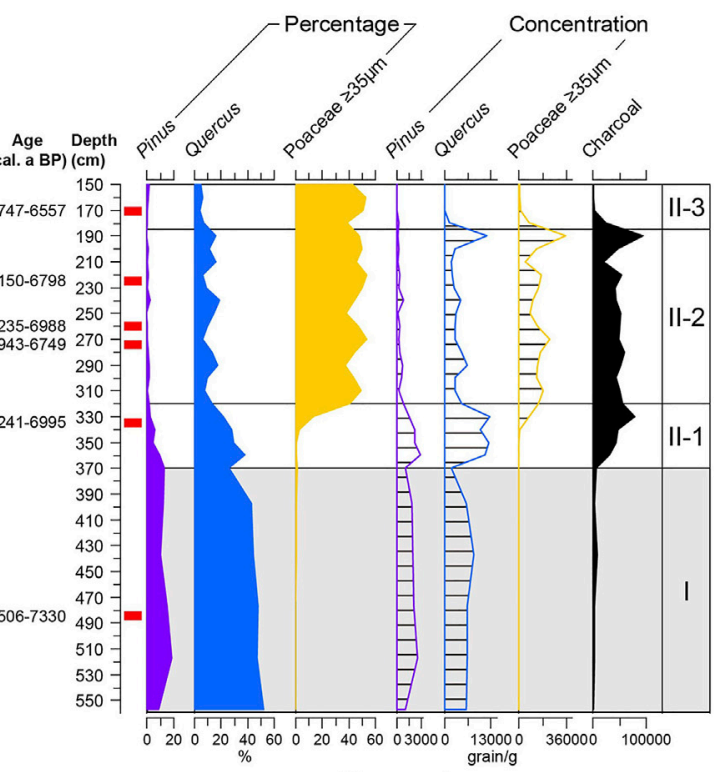

D

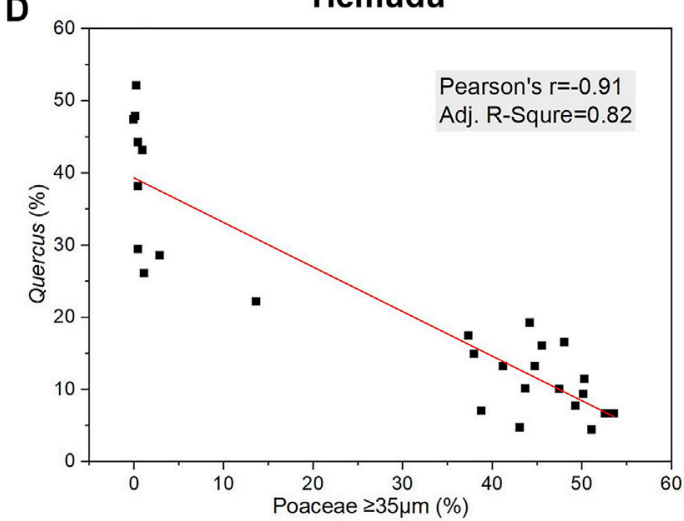

Hemudu

FIGURE 2|Pollen diagram and relationship between selected taxa at the Jingtoushan and Hemudu sites. (A,B) Percentage and concentration pollen diagram with selected taxa. Gray horizontal bars denote the natural layers without human activities. Locations of the dating samples are shown on the right side of the depth scale by red rectangles. (C,D) Relationship between percentage of Quercus and Poaceae $\geq 35 \mu \mathrm{m}$ pollen.

vegetation is under the influence of the East Asian Monsoon and is characterized by subtropical mixed forests of evergreen trees, for example, Lithocarpus, Cyclobalanopsis, and Quercus, and deciduous trees, for example, Liquidambar, Castanea, and Celtis.

Jingtoushan site $\left(30^{\circ} 2^{\prime} \mathrm{N}, 121^{\circ} 22^{\prime} \mathrm{E}\right)$ is situated in the Yaojiang Valley, about $2.3 \mathrm{~km}$ west of the Tianluoshan site and $7.6 \mathrm{~km}$ north of the Hemudu site, with elevation of $2.5 \mathrm{~m}$ above local mean sea level (Zhejiang Provicial Institute of Cultural Relics and Archaeology et al., 2021). The Jingtoushan site was first discovered and drilled in 2014, and the cultural layers were about 7-8 $\mathrm{m}$ below the ground, which was the deepest archaeological site in the coastal region of China. Three sections of No. 4 core were selected for pollen analysis, that is, $4 \mathrm{~h}(1,020-920 \mathrm{~cm}), 4 \mathrm{~g}(920-820 \mathrm{~cm})$, and $4 \mathrm{f}(820-720 \mathrm{~cm})$. The cultural layer $(930-805 \mathrm{~cm})$ was subdivided into three layers: the silt layer $(930-890 \mathrm{~cm})$, the charcoal layer $(890-860 \mathrm{~cm})$, and the shell layer $(860-805 \mathrm{~cm})$, which was formed upon weathered crust and overlaid by thick marine sediments (Supplementary Figure S1). A total of 35 samples were collected at $4 \mathrm{~cm}$ intervals, including 25 samples from the cultural layer and five samples from the natural sediment layers below and above, respectively.

The Hemudu site $\left(29^{\circ} 58^{\prime} \mathrm{N}, 121^{\circ} 21^{\prime} \mathrm{E}\right)$ is situated beside the Yaojiang River and has been excavated twice in 1973 and 1977, covering approximately $50000 \mathrm{~m}^{2}$ (Zhejiang Provincial Institute of Relics and Archaeology, 2003). A 715-cm long core HMD1602 was retrieved from the site reservation of pile dwellings southeast of the Hemudu museum in 2016. The upper $140 \mathrm{~cm}$ was composed of continental and artificial layers that were not analyzed. The sediment of $370-140 \mathrm{~cm}$ was the Hemudu cultural layer and was sampled at $10 \mathrm{~cm}$ intervals. The sediment of $558-370 \mathrm{~cm}$ containing numerous foraminifera and marine diatoms was interpreted as a neritic layer and sampled at approximately $20 \mathrm{~cm}$ intervals (Supplementary Figure S2) (He et al., 2020b). A total of 27 samples were 

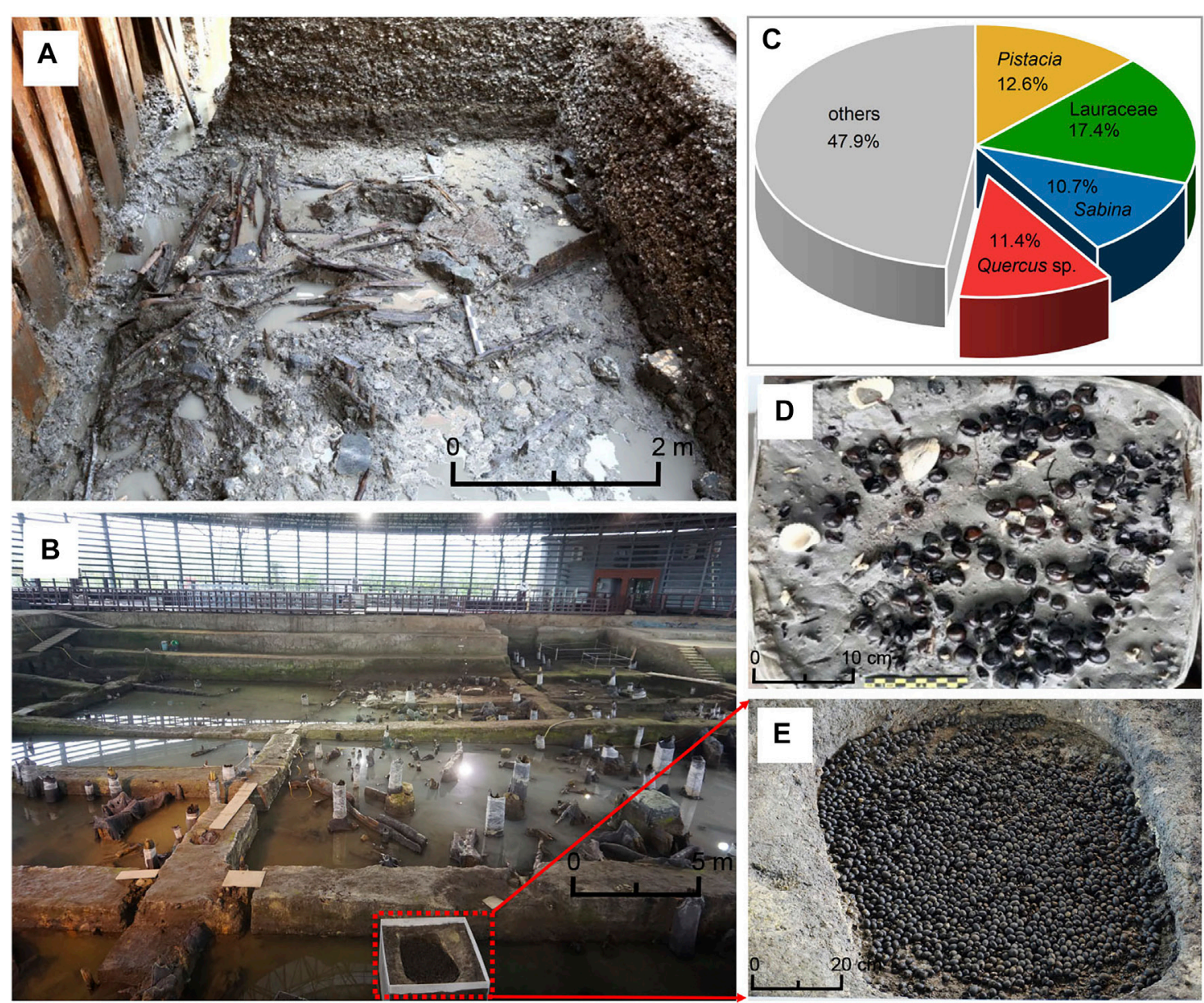

FIGURE 3 | Wooden remains and pits of acorns excavated at the Jingtoushan and Tianluoshan sites. (A) Wooden remains excavated below layer 17 in T508 trenches of the Jingtoushan site, including wooden handle and paddle. (B) Pile dwellings excavated below layer 6 at the Tianluoshan site. (C) Identification of tree species of archaeological woods from the Tianluoshan site (Suzuki et al., 2011). (D,E) Pits of acorns from the Jingtoushan (H13) and Tianluoshan sites.

collected for pollen analysis, including 17 samples from the cultural layer and 10 samples from the natural layers below.

The Yushan site $\left(30^{\circ} 02^{\prime} \mathrm{N}, 121^{\circ} 33^{\prime} \mathrm{E}\right)$ is situated on the eastern entrance of the Yaojiang Valley, $7.3 \mathrm{~km}$ west to the present coastline (Ningbo Municipal Institution of Cultural Relics and Archaeology et al., 2016). The Yushan site was excavated in 2013, and a $275-\mathrm{cm}$ long profile was collected from the south section of trench T0213 (Supplementary Figure S3). The upper $60 \mathrm{~cm}$ of the profile encompassed historic and modern sediment and was not sampled. The lower $215 \mathrm{~cm}$ was subdivided into three natural layers of marine transgression at $275-250 \mathrm{~cm}, 215-180 \mathrm{~cm}$, and $120-60 \mathrm{~cm}$, and two cultural layers of Hemudu Period II $(250-215 \mathrm{~cm})$ and Hemudu Period III-Liangzhu Culture $(180-120 \mathrm{~cm})$ (He et al., 2018). A total of 43 samples were collected at $5 \mathrm{~cm}$ intervals for pollen analysis.

The Xiawangdu site $\left(29^{\circ} 46^{\prime} \mathrm{N}, 121^{\circ} 26^{\prime} \mathrm{E}\right)$ is situated beside the Fenghua River, which merges with Yaojiang River to form Yongjiang River at Ningbo City (Ningbo Municipal Institution of Cultural Relics and Archaeology et al., 2019). This site was excavated in 2017, and a $195-\mathrm{cm}$ long profile sampled was in the west section of trench T0602 (Supplementary Figure S4). The upper $10 \mathrm{~cm}$ of the profile encompassed historic and modern sediment and was not sampled. The lower $185 \mathrm{~cm}$ encompassed three main units, including natural layers of marine transgression at $195-160 \mathrm{~cm}$, cultural layers of Hemudu Period III-IV $(160-50 \mathrm{~cm})$, and Liangzhu Culture $(50-10 \mathrm{~cm})$ (He et al., 2020a). A total of 40 samples were collected at approximately $5 \mathrm{~cm}$ intervals for pollen analysis.

In total, 145 samples were collected from cores/profiles of the four archaeological sites, which were located in the core region of each archaeological site with the most complete cultural sequence and sediments, ranging from the coast to foothills in space and spanning the middle Holocene $(8.2-4.2 \mathrm{cal} \mathrm{ka} \mathrm{BP})$ in time. Previously, pollen records of profiles from the Yushan and Xiawangdu sites have been reported (He et al., 2018; He et al., 2020a). For this study, palynological analysis of the cores at the Jingtoushan (Supplementary Figure S5) and Hemudu (Supplementary Figure S6) sites was conducted to get a full view of human-environment interaction during the whole 

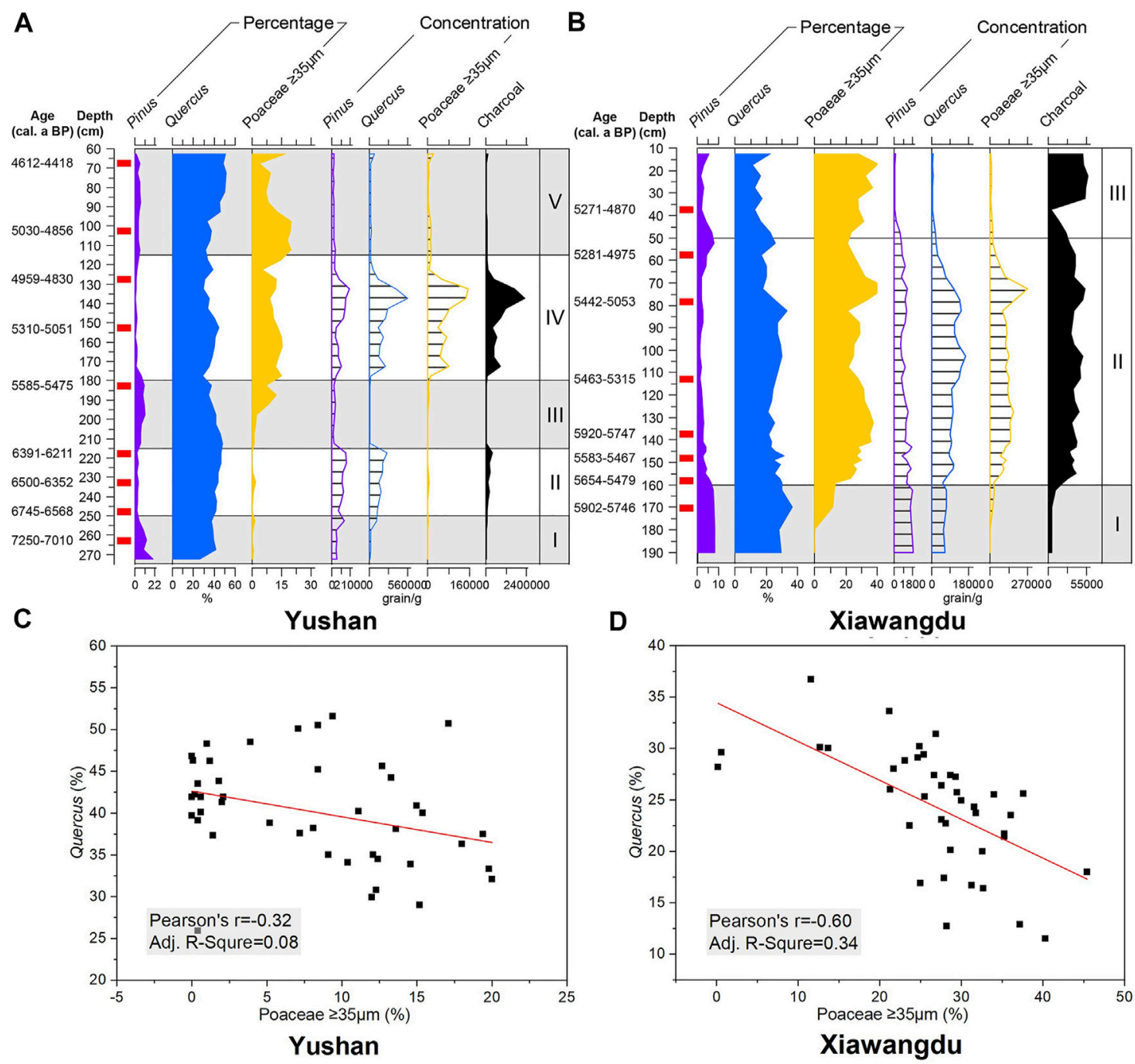

FIGURE 4 | Pollen diagram and relationship between selected taxa at the Yushan and Xiawangdu sites. (A,B) Percentage and concentration pollen diagram with selected taxa. Gray horizontal bars denote the natural layers without human activities. Locations of the dating samples are shown on the right side of the depth scale by red rectangles. (C,D) Relationship between percentage of Quercus and Poaceae $\geq 35 \mu \mathrm{m}$ pollen.

middle Holocene. Each core/profile encompassed both natural (light gray) and cultural layers (dark gray) (Figure 1B) for further comparison of environmental change and human activities.

\section{Radiocarbon Dating}

Thirty-four samples in total were collected for dating, which have been conducted in four radiocarbon laboratories: Beta Analytic (Beta), Peking University (BA), Paleo Labo Co. (PLD), and the University of Georgia (UGa). With regard to the cores at the Jingtoushan and Hemudu sites, plants and charcoal were collected systematically during sampling; as to the profiles of the Yushan and Xiawangdu sites, samples were collected at the boundaries of each layer and screened to retrieve short-lived seeds and charcoal for dating. The radiocarbon ages were calibrated uniformly using the IntCal20 dataset with the OxCal v4.4 program (Bronk Ramsey, 2009; Reimer et al., 2020). Dates of the Jingtoushan site are first published in this study, and details of all the dates are displayed in Table 1 and Figures 2, 4.

\section{Pollen Analysis}

Two grams of each sample were weighed for pollen analysis. Pollen samples were treated according to the standard procedure developed by Moore et al. (1991), and generally, over 400 grains were counted for each sample using a Leica DM 750 microscope at $\times 400$ magnification. Microscopic charcoal was counted on the pollen slides while identifying pollen. Identification of pollen and spores was made with reference to modern and Quaternary atlases (Institute of Botany and South China Institute of Botany, 1982; Wang et al., 1995; Tang et al., 2016). Quercus (oak) pollen included two categories based on the surface, tricolporoidate and size, that is, Quercus-deciduous and Quercusevergreen (including Cyclobalanopsis) (Tang et al., 2018). Poaceae pollen was divided into three size categories $(<35,35-40$, and 

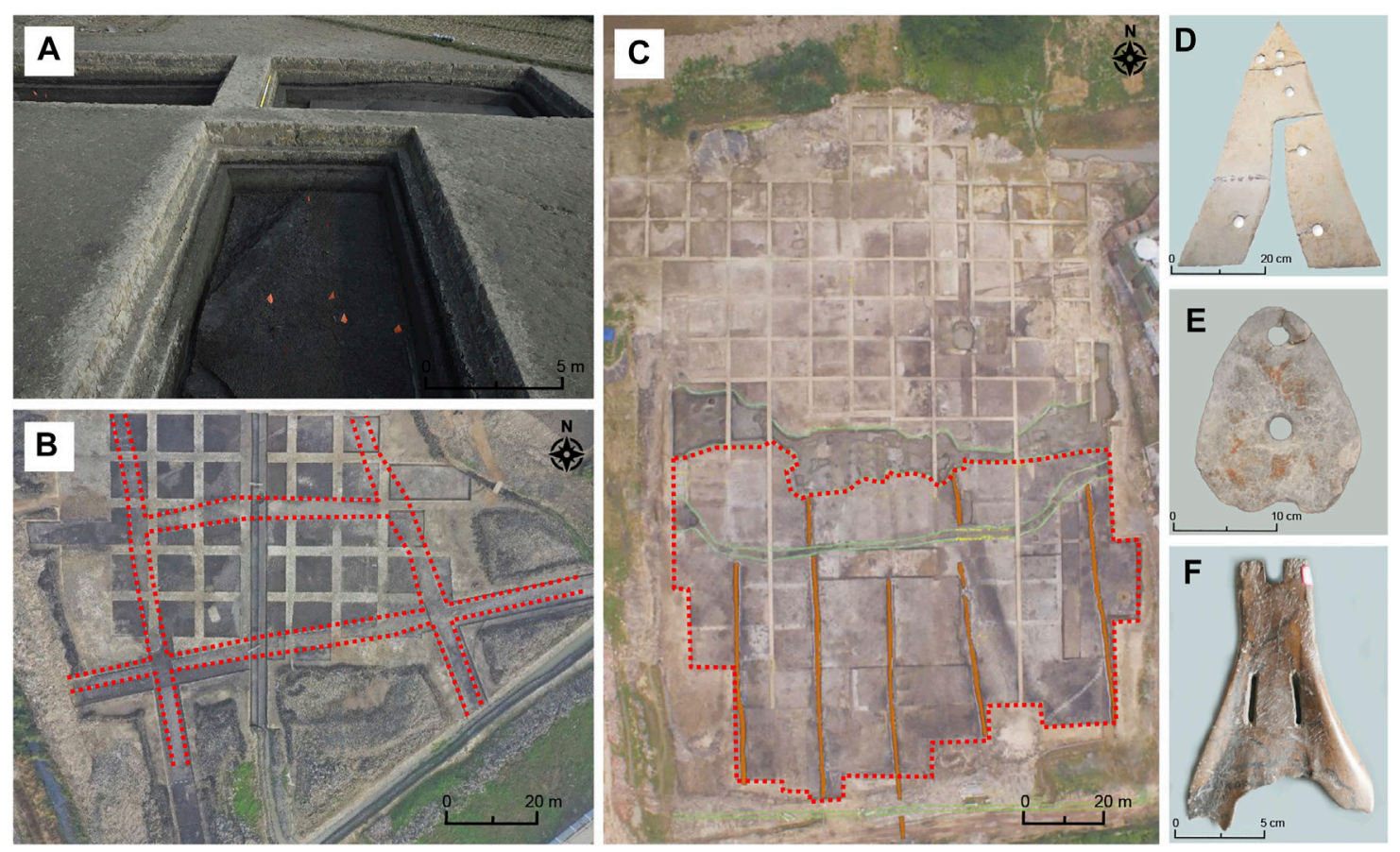

FIGURE 5 | Paddy system and farm tools excavated in the lower Yangtze River. (A) Paddy system in T803 and T703 trenches from the Tianluoshan site, dated 5,290 to 5,040 cal a BP (Zheng et al., 2009). (B) Paddy system excavated at the Shi'ao site, covering about 4,650 m², dated 4,900 to 4,500 cal a BP. (C) Paddy system excavated at the Maoshan site, covering about $55000 \mathrm{~m}^{2}$, dated 4,700 to 4,200 cal a BP (Zhuang et al., 2014). (D) Split type stone plow excavated at the Maoshan site. (E,F) Integrative type stone plow and bone spade excavated at the Xiawangdu site.

$>40 \mu \mathrm{m})$, and the large size category $(\geq 35 \mu \mathrm{m})$ had been identified as domesticated rice pollen in the sediment of eastern China (Yang et al., 2012). Zones in the pollen diagram were divided according to the sediment and pollen assemblages using C2 software (Juggins, 2007). In addition, a correlation analysis between the percentage of Quercus and Poaceae $\geq 35 \mu \mathrm{m}$ pollen was conducted by Origin 2021 software.

\section{RESULTS AND DISCUSSION \\ Deforestation and Rice Cultivation Inside the Archaeological Sites}

In this study, the terrestrial pollen assemblages of the four archaeological sites were all predominated by arboreal Quercus (average 20.4-46.3\%) and herbaceous Poaceae (average 16.9-51.8\%), and exhibited diverse patterns with time. In the natural layers of the Jingtoushan (Zones I and III) and Hemudu (Zone I) sites, the pollen diagram was dominated by the primeval vegetation of Quercus and Pinus. In contrast, the percentage of Quercus declined conspicuously and was progressively replaced by that of ricetype Poaceae $\geq 35 \mu \mathrm{m}$ in the cultural layers of the Jingtoushan (Zone II, 8,100-7,800 cal a BP) and Hemudu (Zone II, 7,100-6,500 cal a BP) sites (Figures 2A,B). However, the percentages were problematic among different sedimentary facies. The decrease of Quercus in the cultural layer may not result from deforestation but be caused by the relative rise of Poaceae $\geq 35 \mu \mathrm{m}$ instead (Li et al., 2012), which could be corroborated by the strong negative correlation between that of Quercus and Poaceae (Figures 2C,D).
In addition, the decline in the percentage of Quercus and the increase of charcoal in the cultural layer of the Jingtoushan (Zone II2) and Hemudu (Zone II-1) sites may imply the management of thinning the stands of acorn using fire to harvest efficiently (Pan et al., 2017). Although large quantities of wooden remains, such as pile dwellings, had been excavated at the Jingtoushan and Tianluoshan sites (Figures 3A, B), only a few were identified as Quercus (11.4\%) (Figure 3C) (Suzuki et al., 2011), which implied that Quercus may have been consciously protected for the collection and storage of acorns (Figures 3D, E) rather than deforestation.

In the profiles of the Yushan and Xiawangdu sites, the concentration of Pinus, Quercus, and Poaceae almost changed synchronously, implying that the relative abundance may not be affected by different sedimentary facies (Figures 4A, B). Moreover, the negative correlation between the percentage of Quercus and Poaceae was weak (Figures 4C, D), indicating these two pollen types change independently and the percentage could reflect the real evolution of local vegetation. In the later stages of the cultural layers of the Yushan (Zone IV, 5,600-5,000 cal a BP) and Xiawangdu (Zone II and III, 5,600-4,300 cal a BP) sites, the decline of the percentage of Quercus and Pinus coincided with the increase of that of Poaceae $\geq 35 \mu \mathrm{m}$ and charcoal, suggesting deforestation of Quercus forest induced by the intensification of rice cultivation. Archaeobotanical research suggested that extensive paddy systems, such as Tianluoshan, Shi'ao (ca 4,650 $\mathrm{m}^{2}$ ), and Maoshan sites (ca $55000 \mathrm{~m}^{2}$ ) (Figures 5A-C) (Zheng et al., 2009; Zhuang et al., 2014), and new farm tools, such as stone plow and bone spade (Figures 5D-F) (Fuller et al., 2008), had been applied 


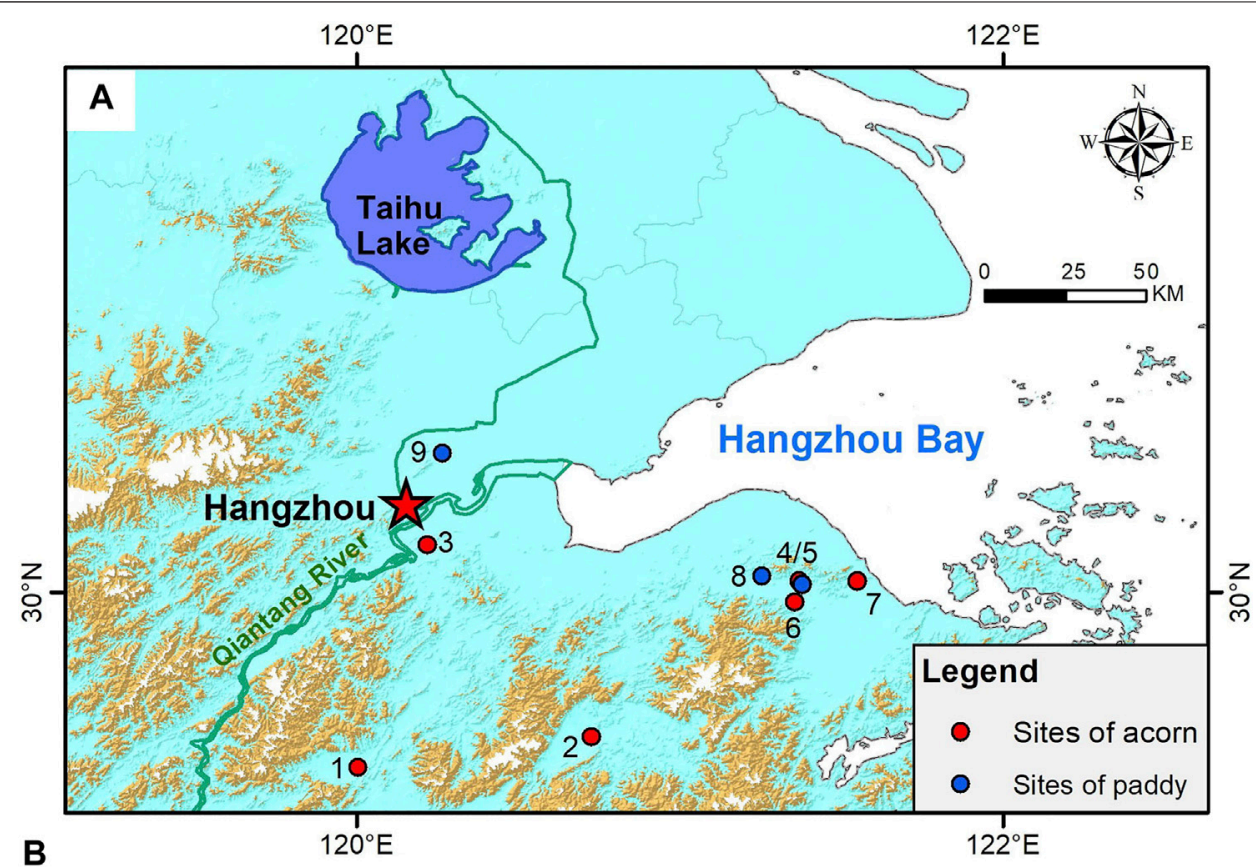

B

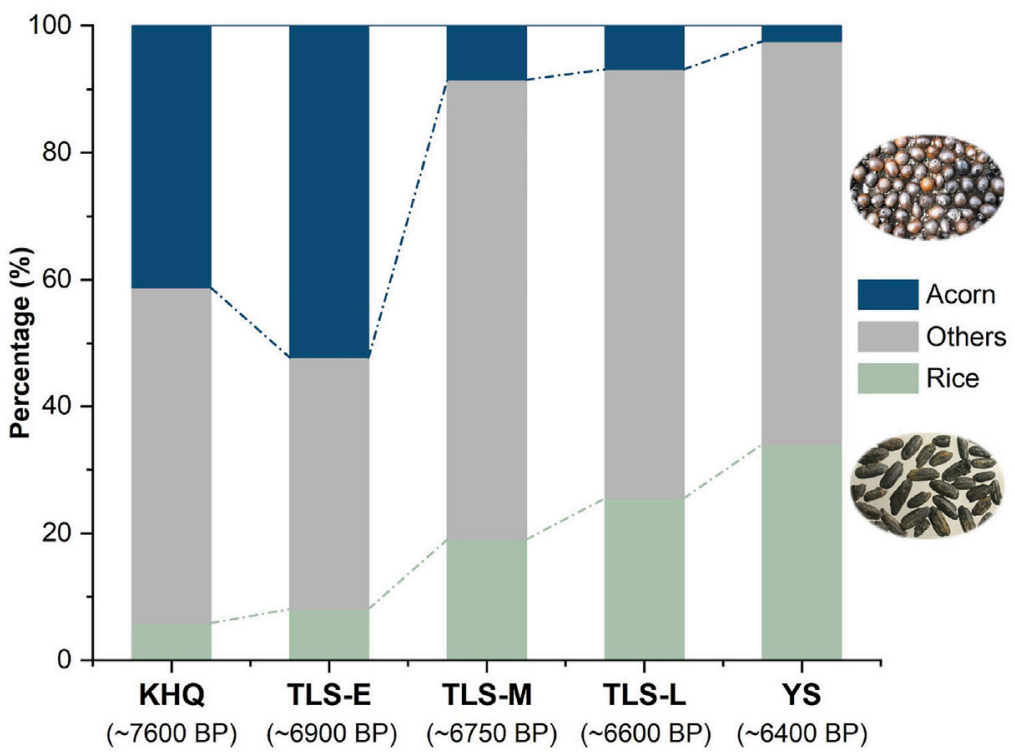

FIGURE 6 | Shift in subsistence from acorn exploitation to rice cultivation. (A) Location of sites with acorns (1-7) and paddy (8-9) excavated in the lower Yangtze River. 1. Shangshan, 2. Xiaohuangshan (Liu et al., 2010b), 3. Kuahuqiao, 4. Jingtoushan, 5. Tianluoshan, 6. Hemudu, 7. Yushan, 8. Shi'ao, 9. Maoshan (Zhuang et al., 2014). (B) Proportion of plant remains from three sites, Kuahuqiao (KHQ) (Pan, 2011), Tianluoshan (TLS) (Fuller et al., 2009), and Yushan (YS) (Zheng et al., 2019), indicating percentages of rice, acorns, and others.

since late Hemudu-Songze and Liangzhu culture, which further support the hypothesis of slash-and-burn practices due to the possible shortage of cultivated land.

\section{Evolution of Subsistence Strategy: Acorn Exploitation vs. Rice Cultivation}

Acorns are the nuts of Quercus sp., which are the constructive species of the subtropical mixed forests of evergreen and deciduous trees in southern China, and constitute the main arboreal component in the palynological records since the late Quaternary (Tang et al., 2018). Ethnographic and archaeological evidence suggest that acorn is a significant resource commonly consumed by Native Americans (Anderson, 2005) and recovered from prehistoric sites in Levant Upper-Palaeolithic (Barlow and Heck, 2002), Japanese Jomon (Takahashi and Hosoya, 2002), and Chinese Early-Middle Neolithic (Yang et al., 2009; Liu et al., 2010a). The earliest evidence for the exploitation of acorn in the lower Yangtze River was starch grains extracted from grinding stones of the Shangshan culture $(10,000-8,500 \mathrm{cal}$ a BP) (Liu 


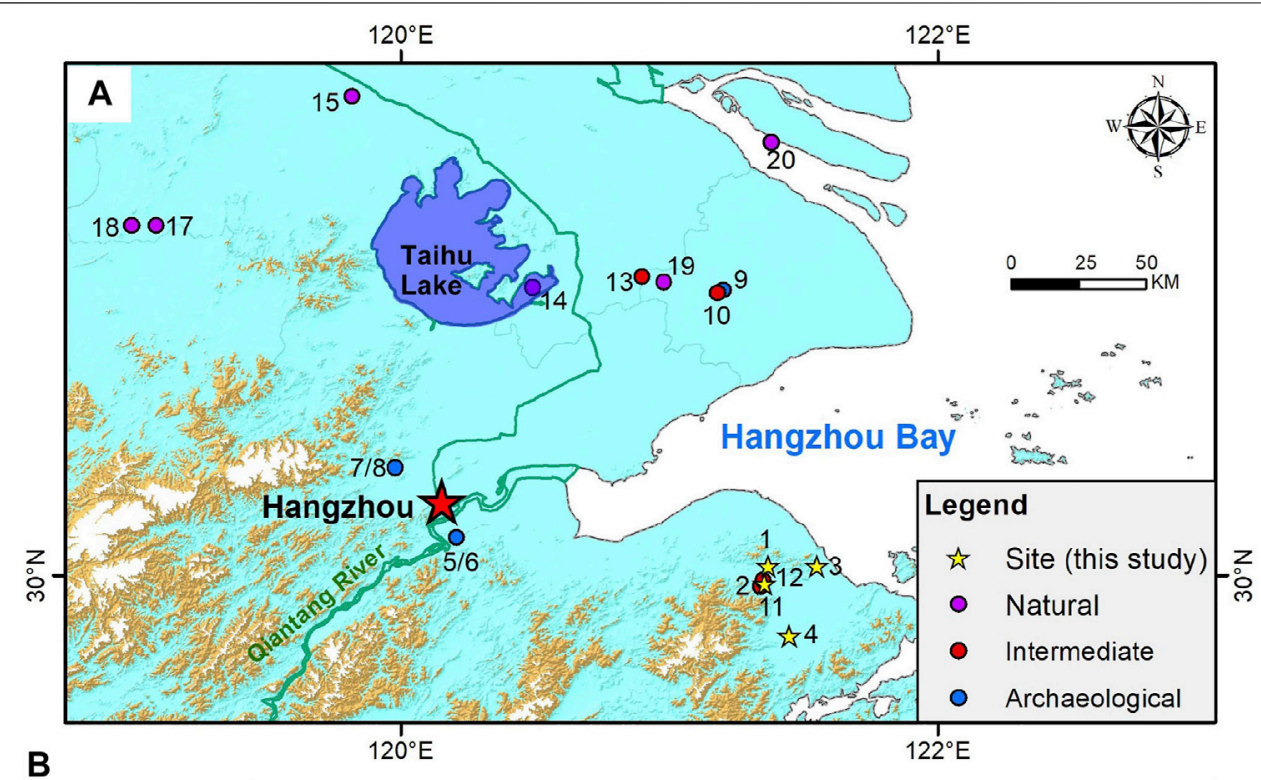

B

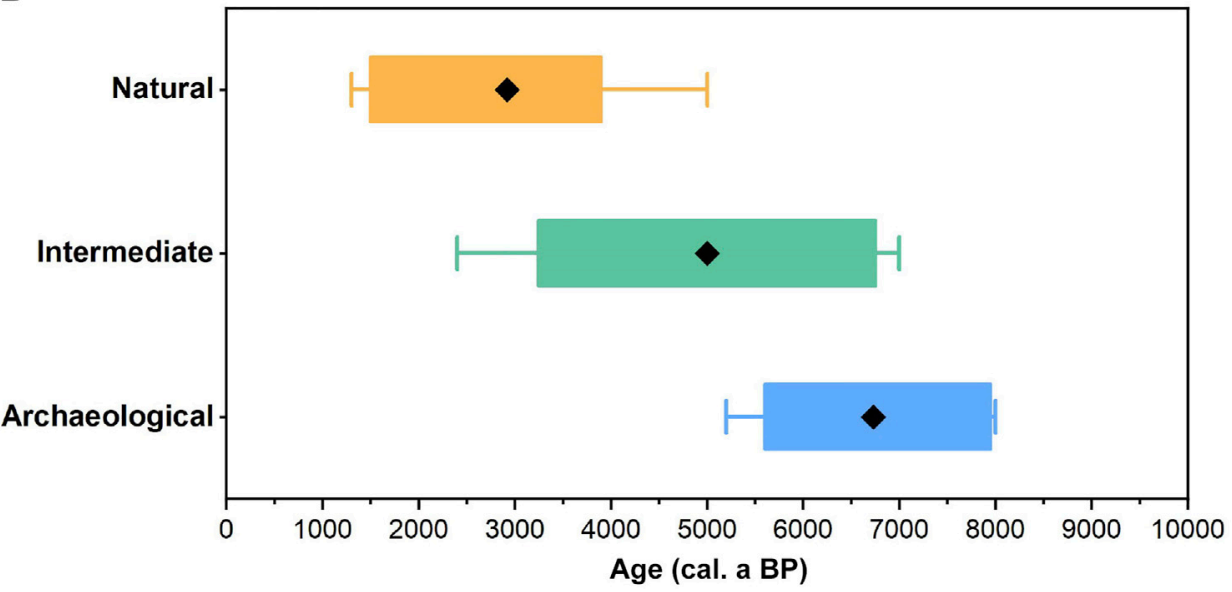

FIGURE 7 | Records of deforestation induced by human activities in the lower Yangtze River. (A) Location of sites with records of deforestation. (B) Boxplot of deforestation timing recorded in natural, intermediate, and archaeological sites. Detailed information of the sites numbered is shown in Table 2.

et al., 2010b; Wang and Jiang, 2021). In addition, large quantities of acorns have been excavated from the storage pits at the Kuahuqiao, Hemudu, and Tianluoshan sites (Figure 6A) (Zhejiang Provincial Institute of Relics and Archaeology, 2003; Fuller et al., 2011; Jiang, 2014).

Acorn is a starch-rich resource that was likely to be exploited as a staple food, predating the establishment of rice agriculture. In the early stages of rice cultivation, acorns accounted for approximately 41.2 and $52.2 \%$ of the whole plant remains at the Kuahuqiao and Tianluoshan sites (Figure 6B), respectively (Fuller et al., 2009; Pan, 2011). In addition, more than twenty storage pits of acorns had been recovered at the Tianluoshan site, and pieces of acorn shells had also been sieved out (Sun, 2013). Thus, in the subsistence strategy, acorn can be used as a staple food for both reserve resources and daily consumption. As a result, the Quercus may have been managed consciously by limiting burning to open habitats and increasing per-tree yield (Pan et al., 2017), and the decline of the concentration of Quercus in the cultural layer of Jingtoushan (Zone II-2, ca 8,000 cal a BP) and Hemudu (Zone II-1, ca 7,000 cal a BP) sites may have just reflected this human activity. Considering the low-level production of rice cultivation prior to $6,000 \mathrm{cal}$ a $\mathrm{BP}$, ancient humans may not sacrifice the resource of acorns to give way to undependable rice cultivation.

However, several factors may restrict the acorn exploitation. First, acorns are a seasonal resource, concentrated from August to October, and their annual yields vary dramatically (Pan et al., 2017). Second, acorns need special processing methods to remove tannins and an appropriate temperature and humidity during storage (Takahashi and Hosoya, 2002). Finally, a cooling trend through the middle to late Holocene may cause regional declines in oaks (Fuller and Qin, 2010). Therefore, the proportion of acorns in plant remains declined significantly to approximately 6.8 and $2.4 \%$ during the later stages of the Tianluoshan and Yushan sites, while that of rice increased progressively to 25.5 and 34.0\% (Figure 6B), respectively (Fuller et al., 2009; Zheng et al., 
TABLE 2 | Detailed information on the start time of deforestation induced by human activities in the lower Yangtze River (see Figure 7 for locations).

\begin{tabular}{|c|c|c|c|c|c|}
\hline \multirow[t]{2}{*}{ No. } & \multirow[t]{2}{*}{ Site } & \multirow{2}{*}{$\begin{array}{l}\text { Start time } \\
\text { (cal. a } \\
\text { BP) }\end{array}$} & \multirow[t]{2}{*}{ Category } & Location & \multirow[t]{2}{*}{ Reference } \\
\hline & & & & $\begin{array}{l}\text { Lat. (N); } \\
\text { Long. (E) }\end{array}$ & \\
\hline 1 & Jingtoushan & 8,000 & Archaeological & $30.03^{\circ}, 121.36^{\circ}$ & This study \\
\hline 2 & Hemudu & 7,000 & Archaeological & $29.96^{\circ}, 121.35^{\circ}$ & This study \\
\hline 3 & Yushan & 5,600 & Archaeological & $30.03^{\circ}, 121.55^{\circ}$ & This study \\
\hline 4 & Xiawangdu & 5,600 & Archaeological & $29.77^{\circ}, 121.44^{\circ}$ & This study \\
\hline 5 & Kuahuqiao & 7,950 & Archaeological & $30.14^{\circ}, 120.21^{\circ}$ & Shu et al. (2010) \\
\hline 6 & Kuahuqiao & 7,750 & Archaeological & $30.14^{\circ}, 120.21^{\circ}$ & Zong et al. (2007) \\
\hline 7 & Liangzhu & 5,200 & Archaeological & $30.4^{\circ}, 119.98^{\circ}$ & Li et al. (2010) \\
\hline 8 & Liangzhu & 4,800 & Archaeological & $30.4^{\circ}, 119.98^{\circ}$ & Liu et al. (2015) \\
\hline 9 & Guangfulin & 4,635 & Archaeological & $31.06^{\circ}, 121.20^{\circ}$ & Tang et al. (2019) \\
\hline 10 & Guangfulin & 7,000 & Intermediate & $31.05^{\circ}, 121.18^{\circ}$ & Itzstein-Davey et al. (2007b) \\
\hline 11 & Hemudu & 6,500 & Intermediate & $29.96^{\circ}, 121.34^{\circ}$ & Liu et al. (2016) \\
\hline 12 & Luojiang & 4,100 & Intermediate & $29.98^{\circ}, 121.35^{\circ}$ & Atahan et al. (2008) \\
\hline 13 & Qingpu & 2,400 & Intermediate & $31.11^{\circ}, 120.9^{\circ}$ & Itzstein-Davey et al. (2007a) \\
\hline 14 & E2A & 5,000 & Natural & $31.07^{\circ}, 120.49^{\circ}$ & Xu et al. (1996) \\
\hline 15 & ZK01 & 3,900 & Natural & $31.78^{\circ}, 119.82^{\circ}$ & Shu et al. (2007) \\
\hline 16 & $\mathrm{ACN}$ & 3,750 & Natural & $31.53^{\circ}, 117.37^{\circ}$ & Chen et al. (2009) \\
\hline 17 & Gaochun & 3,000 & Natural & $31.30^{\circ}, 119.09^{\circ}$ & Yao et al. (2017) \\
\hline 18 & Caoduntou & 2000 & Natural & $31.30^{\circ}, 119.00^{\circ}$ & Okuda et al. (2003) \\
\hline 19 & Dianshan & 1,500 & Natural & $31.09^{\circ}, 120.98^{\circ}$ & Innes et al. (2019) \\
\hline 20 & CM97 & 1,300 & Natural & $31.61^{\circ}, 121.38^{\circ}$ & Yi et al. (2003) \\
\hline
\end{tabular}

2019). As the subsistence economy shifts toward an increasing focus on rice, acorns may degenerate from a staple to a famine food reserve (Hosoya, 2011). The labor input and land use of rice cultivation conflicted with that of acorn exploitation, resulting in the local deforestation that is recorded at the Yushan and Xiawangdu sites.

\section{Timing and Extent of Deforestation Induced by Human Activities}

Deforestation for farming was the main type of impact on land use made by prehistoric humans on vegetation that has been detected in Europe and China since the middle Holocene (Ren, 2000; Fyfe et al., 2015; Roberts et al., 2018). The entire ecological process of human-induced deforestation could be modeled into five stages, that is, primeval vegetation, deforestation, cultivation, abandonment, and restoration, which can be reflected in the palynological records (Li et al., 2008). The pollen assemblage of anthropogenic deforestation was generally characterized by a decrease of zonal broadleaf wood (e.g., Quercus) and a rise of secondary pioneer trees (e.g., Pinus), ferns, and herbs (e.g., Poaceae), accompanied by an increase in charcoal (Zheng et al., 2004; Li et al., 2008; Xu et al., 2010). The lower Yangtze River was densely distributed with over 4,000 archaeological sites during the Neolithic and Bronze Age (Hosner et al., 2016) and was substantially transformed by humans. Based on the relative distance to the archaeological sites, palynological research works on the timing of deforestation induced by human activities can be divided into three categories: natural $(>3 \mathrm{~km})$, intermediate (50 m-3 km), and archaeological sites (Figure 7A), respectively.

The earliest signals of anthropogenic deforestation in the lower Yangtze River could be traced back to ca 8,000 and $7,700 \mathrm{cal}$ a BP from the Jingtoushan and Kuahuqiao sites
(Table 2) (Zong et al., 2007; Shu et al., 2012); however, the average and median dates of deforestation among archaeological sites were ca $7,000 \mathrm{cal}$ a BP. As to the intermediate site that is situated 50-3,000 $\mathrm{m}$ outside the adjacent archaeological site, the timing of deforestation ranged from ca 7,000 to $3,000 \mathrm{cal}$ a BP, with an average and median date of ca 5,000 cal a BP. Finally, the timing of deforestation from the natural sediments ranged from ca 4,000 to $1,500 \mathrm{cal}$ a $\mathrm{BP}$, which was generally later than ca $3,000 \mathrm{cal}$ a BP. Significantly, the timing of deforestation decreased progressively from ca $7,000 \mathrm{cal}$ a $\mathrm{BP}$ of the archaeological to ca $5,000 \mathrm{cal}$ a $\mathrm{BP}$ of the intermediate site and ca 3,000 cal a BP of the natural sites at the end (Figure 7B).

Therefore, the synthesized pattern of pollen records in the lower Yangtze River suggested that possible anthropogenic deforestation in the middle Holocene was confined to local scales (Zhao et al., 2009), and no consistent vegetation change occurred at regional scales induced by human activities as reported previously (Ren, 2006). Instead, the main driver of regional vegetation change at the mid-late Holocene transition in eastern China may be attributed to climatic deterioration (Innes et al., 2014). In general, the effects of human disturbance on vegetation at local scales intensified gradually from archaeological to intermediate sites since the middle Holocene, and became an increasingly important factor in the vegetation of natural sites at regional scales until the last 3,000 years (Liu and Qiu, 1994; Zheng et al., 2021), which coincided with a noticeable increase in the number of archaeological sites after 3,500 cal a BP in southern China (Hosner et al., 2016).

\section{CONCLUSION}

In this study, synthesized palynological analysis was applied to the Jingtoushan, Hemudu, Yushan, and Xiawangdu sites, and 
shed light on the timing, extent, and process of deforestation accompanied by the intensification of rice cultivation in the lower Yangtze River. Although natural vegetation had already been altered at the Jingtoushan site around $8,000 \mathrm{cal}$ a BP, it was more likely to be management of acorns by limiting burning to open habitats and increasing per-tree yield. As the subsistence economy shifted toward rice cultivation after $6,000 \mathrm{cal}$ a $\mathrm{BP}$, real deforestation for agriculture may happen due to conflict of acorn exploitation on labor input and land use, which was just confined to local scale inside the archaeological site. Possible synchronous deforestation that occurred in archaeological, intermediate, and natural sites at regional scales may be postponed until the last 3,000 years.

\section{DATA AVAILABILITY STATEMENT}

The original contributions presented in the study are included in the article/Supplementary Material; further inquiries can be directed to the corresponding authors.

\section{AUTHOR CONTRIBUTIONS}

$\mathrm{HL}$ and $\mathrm{KH}$ designed the research plan. GS, YZ, HZ, SL, and YL provided the archaeological samples. YW and JZ assisted in the

\section{REFERENCES}

Anderson, M. (2005). Tending the Wild: Native American Knowledge and Management of California's Natural Resources. Berkeley: University of California Press.

Atahan, P., Itzstein-Davey, F., Taylor, D., Dodson, J., Qin, J., Zheng, H., et al. (2008). Holocene-aged Sedimentary Records of Environmental Changes and Early Agriculture in the Lower Yangtze, China. Quat. Sci. Rev. 27, 556-570. doi:10.1016/j.quascirev.2007.11.003

Barlow, K. R., and Heck, M. (2002). "More on Acorn Eating during the Natufian: Expected Patterning in Diet and the Archaeological Record of Subsistence," in Hunter-gatherer Archaeobotany: Perspective from the Northern Temperate Zone. Editors S. L. R. Mason and J. G. Hather (London: University College London Press), 128-145.

Bronk Ramsey, C. (2009). Bayesian Analysis of Radiocarbon Dates. Radiocarbon 51, 337-360. doi:10.1017/S0033822200033865

Chen, W., Wang, W., and Dai, X. (2009). Holocene Vegetation History with Implications of Human Impact in the Lake Chaohu Area, Anhui Province, East China. Veget Hist. Archaeobot 18, 137-146. doi:10.1007/s00334-008-0173-7

Cheng, Z., Weng, C., Steinke, S., and Mohtadi, M. (2018). Anthropogenic Modification of Vegetated Landscapes in Southern China from 6,000 Years Ago. Nat. Geosci 11, 939-943. doi:10.1038/s41561-018-0250-1

Fuller, D. Q., and Qin, L. (2010). Declining oaks, Increasing Artistry, and Cultivating rice: the Environmental and Social Context of the Emergence of Farming in the Lower Yangtze Region. Environ. Archaeology 15, 139-159. doi:10.1179/146141010x12640787648531

Fuller, D. Q., Qin, L., and Harvey, E. (2008). "Evidence for a Late Onset of Agriculture in the Lower Yangtze Region and Challenges for an Archaeobotany of rice," in Past Human Migrations in East Asia: Matching Archaeology, Linguistics and Genetics. Editors A. Sanchez-Mazas, R. Blench, M. D. Blench, I. Peiros, and M. Lin (London: Routledge), 40-83.

Fuller, D. Q., Qin, L., Zhao, Z., Zheng, Y., Hosoya, L., Chen, X., et al. (2011). "Archaeobotanical Analysis at Tianluoshan: Evidence for Wild-Food Gathering, rice Cultivation and the Process of the Evolution of Morphologically Domesticated collection and extraction of samples. $\mathrm{KH}$ analyzed the data and created the figures. $\mathrm{KH}$ and $\mathrm{HL}$ wrote and revised the manuscript.

\section{FUNDING}

This study was supported by the Natural Science Foundation of China (Nos 41830322, 41902187, and T2192954), the Strategic Priority Research Program of the Chinese Academy of Sciences (No. XDB26000000), and the China Postdoctoral Science Foundation (No. 2020M670444).

\section{ACKNOWLEDGMENTS}

We would like to thank Deke Xu, Xiujia Huan, Yong Ge, Can Wang, Qing Yang, and Zhujun Hu for their assistance in sample collection. Constructive comments and suggestions from the editor and reviewers are gratefully acknowledged.

\section{SUPPLEMENTARY MATERIAL}

The Supplementary Material for this article can be found online at: https://www.frontiersin.org/articles/10.3389/feart.2022.849501/ full\#supplementary-material

rice," in Integrated Studies on the Natural Remains from Tianluoshan. Editors Center for the Study of Chinese Archaeology in Peking University and Zhejiang Province Institute of Archaeology and Cultural Heritage (Beijing: Cultural Relics Press), 47-96. (in Chinese).

Fuller, D. Q., Qin, L., Zheng, Y., Zhao, Z., Chen, X., Hosoya, L., et al. (2009). The Domestication Process and Domestication Rate in rice: Spikelet Bases from the Lower Yangtze. Science 323, 1607-1610. doi:10.1126/science.1166605

Fyfe, R. M., Woodbridge, J., and Roberts, N. (2015). From forest to farmland: Pollen-inferred Land Cover Change across Europe Using the Pseudobiomization Approach. Glob. Change Biol. 21, 1197-1212. doi:10. $1111 /$ gcb. 12776

He, K., Lu, H., Zheng, H., Yang, Q., Sun, G., Zheng, Y., et al. (2020b). Role of Dynamic Environmental Change in Sustaining the Protracted Process of rice Domestication in the Lower Yangtze River. Quat. Sci. Rev. 242, 106456. doi:10. 1016/j.quascirev.2020.106456

He, K., Lu, H., Zheng, Y., Zhang, J., Xu, D., Huan, X., et al. (2018). MiddleHolocene Sea-Level Fluctuations Interrupted the Developing Hemudu Culture in the Lower Yangtze River, China. Quat. Sci. Rev. 188, 90-103. doi:10.1016/j. quascirev.2018.03.034

He, K., Lu, H., Li, Y., Ding, F., Zhang, J., and Wang, C. (2020a). Cultural Response to Middle Holocene Sea-level Fluctuations in Eastern China: a Multi-proxy Approach. Boreas 49, 71-88. doi:10.1111/bor.12421

Hosner, D., Wagner, M., Tarasov, P. E., Chen, X., and Leipe, C. (2016). Spatiotemporal Distribution Patterns of Archaeological Sites in China during the Neolithic and Bronze Age: An Overview. The Holocene 26, 1576-1593. doi:10.1177/0959683616641743

Hosoya, L. A. (2011). Staple or Famine Food?: Ethnographic and Archaeological Approaches to Nut Processing in East Asian Prehistory. Archaeol Anthropol. Sci. 3, 7-17. doi:10.1007/s12520-011-0059-y

Hu, L., Chao, Z., Gu, M., Li, F., Chen, L., Liu, B., et al. (2013). Evidence for a Neolithic Age Fire-Irrigation Paddy Cultivation System in the Lower Yangtze River Delta, China. J. Archaeological Sci. 40, 72-78. doi:10.1016/j.jas.2012. 04.021

Hu, Y., Zhou, B., Lu, Y., Zhang, J., Min, S., Dai, M., et al. (2020). Abundance and Morphology of Charcoal in Sediments Provide No Evidence of Massive Slash- 
And-Burn Agriculture during the Neolithic Kuahuqiao Culture, China. PLoS One 15, e0237592. doi:10.1371/journal.pone.0237592

Innes, J. B., Zong, Y., Chen, Z., Chen, C., Wang, Z., and Wang, H. (2009). Environmental History, Palaeoecology and Human Activity at the Early Neolithic Forager/cultivator Site at Kuahuqiao, Hangzhou, Eastern China. Quat. Sci. Rev. 28, 2277-2294. doi:10.1016/j.quascirev.2009.04.010

Innes, J. B., Zong, Y., Wang, Z., and Chen, Z. (2014). Climatic and Palaeoecological Changes during the Mid- to Late Holocene Transition in Eastern China: HighResolution Pollen and Non-pollen Palynomorph Analysis at Pingwang, Yangtze Coastal Lowlands. Quat. Sci. Rev. 99, 164-175. doi:10.1016/j. quascirev.2014.06.013

Innes, J. B., Zong, Y., Xiong, H., Wang, Z., and Chen, Z. (2019). Pollen and Nonpollen Palynomorph Analyses of Upper Holocene Sediments from Dianshan, Yangtze Coastal Lowlands, China: Hydrology, Vegetation History and Human Activity. Palaeogeogr. Palaeoclimatol. Palaeoecol. 523, 30-47. doi:10.1016/j. palaeo.2019.03.009

Institute of Botany and South China Institute of Botany (1982). Angiosperm Pollen Flora of Tropical and Subtropical China. Beijing: Science Press. (in Chinese).

Itzstein-Davey, F., Atahan, P., Dodson, J., Taylor, D., and Zheng, H. (2007b). A Sediment-Based Record of Lateglacial and Holocene Environmental Changes from Guangfulin, Yangtze delta, Eastern China. The Holocene 17, 1221-1231. doi:10.1177/0959683607085128

Itzstein-Davey, F., Atahan, P., Dodson, J., Taylor, D., and Zheng, H. (2007a). Environmental and Cultural Changes during the Terminal Neolithic: Qingpu, Yangtze delta, Eastern China. The Holocene 17, 875-887. doi:10.1177/ 0959683607080517

Jiang, L. P. (2014). Research on Kuahuqiao Culture. Beijing: Science Press.

Juggins, S. (2007). C2: Software for Ecological and Palaeoecological Data Analysis and Visualisation (User Guide Version 1.5). Newcastle upon Tyne: Newcastle University, 1-77.

Kaplan, J. O., Krumhardt, K. M., Ellis, E. C., Ruddiman, W. F., Lemmen, C., and Goldewijk, K. K. (2011). Holocene Carbon Emissions as a Result of Anthropogenic Land Cover Change. The Holocene 21, 775-791. doi:10.1177/ 0959683610386983

Kaplan, J. O., Krumhardt, K. M., and Zimmermann, N. (2009). The Prehistoric and Preindustrial Deforestation of Europe. Quat. Sci. Rev. 28, 3016-3034. doi:10. 1016/j.quascirev.2009.09.028

Li, C., Zheng, Y., Yu, S., Li, Y., and Shen, H. (2012). Understanding the Ecological Background of rice Agriculture on the Ningshao Plain during the Neolithic Age: Pollen Evidence from a Buried Paddy Field at the Tianluoshan Cultural Site. Quat. Sci. Rev. 35, 131-138. doi:10.1016/j.quascirev.2012.01.007

Li, X., Dodson, J., Zhou, J., and Zhou, X. (2009). Increases of Population and Expansion of rice Agriculture in Asia, and Anthropogenic Methane Emissions since 5000BP. Quat. Int. 202, 41-50. doi:10.1016/j.quaint.2008.02.009

Li, Y., Wu, J., Hou, S., Shi, C., Mo, D., Liu, B., et al. (2010). Palaeoecological Records of Environmental Change and Cultural Development from the Liangzhu and Qujialing Archaeological Sites in the Middle and Lower Reaches of the Yangtze River. Quat. Int. 227, 29-37. doi:10.1016/j.quaint.2010.05.015

Li, Y., Zhou, L., and Cui, H. (2008). Pollen Indicators of Human Activity. Sci. Bull. 53, 1281-1293. doi:10.1007/s11434-008-0181-0

Liu, K.-B., and Qiu, H. (1994). Late-Holocene Pollen Records of Vegetational Changes in China:Climate or Human Disturbance? Terr. Atmos. Ocean. Sci. 5, 393-410. doi:10.3319/tao.1994.5.3.393(PAGES)

Liu, L., Field, J., Fullagar, R., Zhao, C., Chen, X., and Yu, J. (2010a). A Functional Analysis of Grinding Stones from an Early Holocene Site at Donghulin, North China. J. Archaeological Sci. 37, 2630-2639. doi:10.1016/j.jas.2010.05.023

Liu, L., Field, J., Weisskopf, A., Webb, J., Jiang, L., Wang, H., et al. (2010b). The Exploitation of Acorn and rice in Early Holocene Lower Yangzi River, China. Acta Anthropologica Sinica 29, 317-333.

Liu, Y., Sun, Q., Fan, D., Lai, X., Xu, L., Finlayson, B., et al. (2016). Pollen Evidence to Interpret the History of rice Farming at the Hemudu Site on the Ningshao Coast, Eastern China. Quat. Int. 426, 195-203. doi:10.1016/ j.quaint.2016.05.016

Liu, Y., Sun, Q., Thomas, I., Zhang, L., Finlayson, B., Zhang, W., et al. (2015). Middle Holocene Coastal Environment and the Rise of the Liangzhu City Complex on the Yangtze delta, China. Quat. Res. 84, 326-334. doi:10.1016/j. yqres.2015.10.001
Lu, H., Liu, Z., Wu, N., Berné, S., Saito, Y., Liu, B., et al. (2002). Rice Domestication and Climatic Change: Phytolith Evidence from East China. Boreas 31, 378-385. doi:10.1111/j.1502-3885.2002.tb01081.x

Moore, P. D., Webb, J. A., and Collison, M. E. (1991). Pollen Analysis. Oxford, U.K: Blackwell scientific publications.

Mottl, O., Flantua, S. G. A., Bhatta, K. P., Felde, V. A., Giesecke, T., Goring, S., et al. (2021). Global Acceleration in Rates of Vegetation Change over the Past 18,000 Years. Science 372, 860-864. doi:10.1126/science.abg1685

Ningbo Municipal Institution of Cultural Relics and Archaeology, Department of Archaeology and Museology at Renmin University of China, Fenghua Administrationof Cultural Relics Preservation (2019). Brief Report on the Excavatation of Fangqiao Locality of Xiawangdu Site in Ningbo City, Zhejiang, 2017. Archaeology, 3-26. (in Chinese).

Ningbo Municipal Institution of Cultural Relics and Archaeology, Zhenhai Administration of Cultural Relics Preservation, and Research Center for Cultural Heritage Preservation, J.U. (2016). Stagel Excavation Report of the Yushan Site in Zhenhai, Ningbo, Zhejiang. Southeast Cult., 23-37. (in Chinese).

Okuda, M., Sato, Y., Tang, L. H., Takahashi, M., Toyama, S., Yano, A., et al. (2003). Late Holocene Vegetation and Environment at Cauduntou, West of Yangtze Delta, SW Jiangsu Province, East China. Quat. Int. 105, 39-47. doi:10.1016/ s1040-6182(02)00149-0

Olofsson, J., and Hickler, T. (2008). Effects of Human Land-Use on the Global Carbon Cycle during the Last 6,000 Years. Veget Hist. Archaeobot 17, 605-615. doi:10.1007/s00334-007-0126-6

Pan, Y. (2011). Resource Production in the Yangzi delta and Qiantang River Valley from 10000 to 6000 BP: A Palaeoethnobotanical and Human Ecological Investigation. Doctor. Shanghai: Fudan University.

Pan, Y., Zheng, Y., and Chen, C. (2017). "Human Ecology of the Early Neolithic Kuahuqiao Culture in East Asia," in Handbook of East and Southeast Asian Archaeology. Editors J. Habu, P. V. Lape, J. W. Olsen, and A. M. Eastep (New York: Springer), 347-377. doi:10.1007/978-1-4939-6521-2_23

Reimer, P. J., Austin, W. E. N., Bard, E., Bayliss, A., Blackwell, P. G., Bronk Ramsey, C., et al. (2020). The IntCal20 Northern Hemisphere Radiocarbon Age Calibration Curve (0-55 Cal kBP). Radiocarbon 62, 725-757. doi:10.1017/ RDC.2020.41

Ren, G. (2006). Changes in forest Cover in China during the Holocene. Veget Hist. Archaeobot 16, 119-126. doi:10.1007/s00334-006-0075-5

Ren, G. (2000). Decline of the Mid- to Late Holocene Forests in China: Climatic Change or Human Impact? J. Quat. Sci. 15, 273-281. doi:10.1002/(sici)10991417(200003)15:3<273::aid-jqs504>3.0.co;2-2

Roberts, N., Fyfe, R. M., Woodbridge, J., Gaillard, M.-J., Davis, B. A. S., Kaplan, J. O., et al. (2018). Europe's Lost Forests: a Pollen-Based Synthesis for the Last 11,000 Years. Sci. Rep. 8, 716. doi:10.1038/s41598-017-18646-7

Ruddiman, W. F., Ellis, E. C., Kaplan, J. O., and Fuller, D. Q. (2015). Defining the Epoch We Live in. Science 348, 38-39. doi:10.1126/science.aaa7297

Ruddiman, W. F., Fuller, D. Q., Kutzbach, J. E., Tzedakis, P. C., Kaplan, J. O., Ellis, E. C., et al. (2016). Late Holocene Climate: Natural or Anthropogenic? Rev. Geophys. 54, 93-118. doi:10.1002/2015rg000503

Ruddiman, W. F. (2003). The Anthropogenic Greenhouse Era Began Thousands of Years Ago. Climatic Change 61, 261-293. doi:10.1023/b:clim.0000004577. 17928.fa

Shu, J., Wang, W., and Jiang, L. (2012). Did Alder (Alnus) Fires Trigger rice Cultivation in the Lower Reaches of the Yangtze River, East China? Palaeoworld 21, 69-73. doi:10.1016/j.palwor.2012.02.003

Shu, J., Wang, W., Jiang, L., and Takahara, H. (2010). Early Neolithic Vegetation History, Fire Regime and Human Activity at Kuahuqiao, Lower Yangtze River, East China: New and Improved Insight. Quat. Int. 227, 10-21. doi:10.1016/j. quaint.2010.04.010

Shu, J., Wang, W., and Chen, W. (2007). Holocene Vegetation and Environment Changes in the New Taihu Plain, Jiangsu Province, east China. Acta Micropalaeontologica Sinica 24, 210-221. (in Chinese with English abstract).

Stephens, L., Fuller, D., Boivin, N., Rick, T., Gauthier, N., Kay, A., et al. (2019). Archaeological Assessment Reveals Earth's Early Transformation through Land Use. Science 365, 897-902. doi:10.1126/science.aax1192

Sun, G. P. (2013). "Recent Research on the Hemudu Culture and the Tianluoshan Site," in A Companion to Chinese Archaeology. Editor A. P. Underhill (West Sussex, UK: Wiley-Blackwell), 555-573. 
Suzuki, S., Zheng, Y., Noshiro, S., Oyama, M., Nakamura, S., and Murakami, Y. (2011). "Identification of Tree Species of Archaeological Woods from Tianluoshan Site in Zhejiang Province," in Integrated Studies on the Natural Remains from Tianluoshan. Editors Center for the Study of Chinese Archaeology in Peking University and Zhejiang Province Institute of Archaeology and Cultural Heritage (Beijing: Cultural Relics Press), 108-117. (in Chinese).

Takahashi, R., and Hosoya, L. (2002). "Nut Exploitation in Jomon Society," in Hunter-gatherer Archaeobotany: Perspective from the Northern Temperate Zone. Editors S. L. R. Mason and J. G. Hather (London: University College London Press), 146-155.

Tang, L., Shu, J., Chen, J., and Wang, Z. (2019). Mid- to Late Holocene Vegetation Change Recorded at a Neolithic Site in the Yangtze Coastal plain, East China. Quat. Int. 519, 122-130. doi:10.1016/j.quaint.2018.12.031

Tang, L., Li, C., Zhang, X., Shao, J., Zhou, Z., and Ling, C. (2018). Pollen Morphology of Fagaceae in Quaternary Deposits of China and its Relationship with Climatic and Geographic Characters. Acta Palaeontologica Pol. 57, 387-410. (in Chinese with English abstract).

Tang, L., Mao, L., Shu, J., Li, C., Shen, C., and Zhou, Z. (2016). Handbook of Quaternary Pollen and Spores in China. Beijing: Science Press. (in Chinese).

Wang, F., Chien, N., Zhang, Y., and Yang, H. (1995). Pollen Flora of China. 2nd ed. Beijing: Science Press. (in Chinese).

Wang, H. M. (2000). The Hemudu Sites and the Hemudu Culture. Southeast Cult., 15-22. (in Chinese with English abstract).

Wang, J., and Jiang, L. (2021). Intensive Acorn Processing in the Early Holocene of Southern China. The Holocene, 095968362110417. doi:10.1177/ 09596836211041732

Xu, D., Lu, H., Wu, N., and Liu, Z. (2010). 30 000-Year Vegetation and Climate Change Around the East China Sea Shelf Inferred from a High-Resolution Pollen Record. Quat. Int. 227, 53-60. doi:10.1016/j.quaint.2010.04.015

Xu, X., Chang, W., and Liu, J. (1996). Changes in Vagetation and Climate in the Taihu Lake basin during the Last 11000 Years. Acta Palaeontologica Sinica 35, 175-186. (in Chinese with English abstract).

Yang, S., Zheng, Z., Huang, K., Zong, Y., Wang, J., Xu, Q., et al. (2012). Modern Pollen Assemblages from Cultivated rice fields and rice Pollen Morphology: Application to a Study of Ancient Land Use and Agriculture in the Pearl River Delta, China. The Holocene 22, 1393-1404. doi:10.1177/ 0959683612449761

Yang, X., Yu, J., Lü, H., Cui, T., Guo, J., and Ge, Q. (2009). Starch Grain Analysis Reveals Function of Grinding Stone Tools at Shangzhai Site, Beijing. Sci. China Ser. D-earth Sci. 52, 1164-1171. doi:10.1007/s11430-009-0089-9

Yao, F., Ma, C., Zhu, C., Li, J., Chen, G., Tang, L., et al. (2017). Holocene Climate Change in the Western Part of Taihu Lake Region, East China. Palaeogeogr. Palaeoclimatol. Palaeoecol. 485, 963-973. doi:10.1016/j.palaeo.2017.08.022

Yi, S., Saito, Y., Zhao, Q., and Wang, P. (2003). Vegetation and Climate Changes in the Changjiang (Yangtze River) Delta, China, during the Past 13,000 Years Inferred from Pollen Records. Quat. Sci. Rev. 22, 1501-1519. doi:10.1016/ s0277-3791(03)00080-5

Zheng, Y., Sun, G., Qini, L., Li, C., Wu, X., and Chen, X. (2009). Rice Fields and Modes of Rice Cultivation Between 5000 and 2500 BC in East China. J. Archaeological Sci. 36, 2609-2616. doi:10.1016/j.jas.2009.09.026
Zhao, Y., Yu, Z., Chen, F., Zhang, J., and Yang, B. (2009). Vegetation Response to Holocene Climate Change in Monsoon-Influenced Region of China. Earth-Science Rev. 97, 242-256. doi:10.1016/j.earscirev.2009. 10.007

Zhejiang Provicial Institute of Cultural Relics and Archaeology, Ningbo Institute of Cultural Heritage Management, and Yuyao Hemudu Site Museum (2021). Brief Report on the Excavatation of the Neolithic Site at Jingtoushan in Yuyao City, Zhejiang. Archaeology, 3-26. (in Chinese).

Zhejiang Provincial Institute of Relics and Archaeology (2003). Hemudu Site: The Archaeological Excavation of the Neolithic Sites. Beijing: Cultural Relics Press. (in Chinese).

Zheng, X., Lei, S., Wang, J., and Zhao, Z. (2019). Analysis of Flotation Results from the Yushan Site in Ningbo City. Agric. Archaeology, 21-27. (In Chinese with English abstract).

Zheng, Z., Deng, Y., Zhang, H., Yu, R., and Chen, Z. (2004). Holocene Environmental Changes in the Tropical and Subtropical Areas of the South China and the Relation to Human Activities. Quat. Res. 24, 387-393. (in Chinese with English abstract).

Zheng, Z., Ma, T., Roberts, P., Li, Z., Yue, Y., Peng, H., et al. (2021). Anthropogenic Impacts on Late Holocene Land-Cover Change and Floristic Biodiversity Loss in Tropical southeastern Asia. Proc. Natl. Acad. Sci. USA 118, e2022210118. doi:10.1073/pnas.2022210118

Zhuang, Y., Ding, P., and French, C. (2014). Water Management and Agricultural Intensification of rice Farming at the Late-Neolithic Site of Maoshan, Lower Yangtze River, China. The Holocene 24, 531-545. doi:10.1177/ 0959683614522310

Zong, Y., Chen, Z., Innes, J. B., Chen, C., Wang, Z., and Wang, H. (2007). Fire and Flood Management of Coastal Swamp Enabled First rice Paddy Cultivation in east China. Nature 449, 459-462. doi:10.1038/nature06135

Zuo, X., Lu, H., Jiang, L., Zhang, J., Yang, X., Huan, X., et al. (2017). Dating rice Remains through Phytolith Carbon-14 Study Reveals Domestication at the Beginning of the Holocene. Proc. Natl. Acad. Sci. USA 114, 6486-6491. doi:10. 1073/pnas.1704304114

Conflict of Interest: The authors declare that the research was conducted in the absence of any commercial or financial relationships that could be construed as a potential conflict of interest.

Publisher's Note: All claims expressed in this article are solely those of the authors and do not necessarily represent those of their affiliated organizations, or those of the publisher, the editors, and the reviewers. Any product that may be evaluated in this article, or claim that may be made by its manufacturer, is not guaranteed or endorsed by the publisher.

Copyright $\odot 2022 \mathrm{He}, \mathrm{Lu}$, Sun, Wang, Zheng, Zheng, Lei, Li and Zhang. This is an open-access article distributed under the terms of the Creative Commons Attribution License (CC BY). The use, distribution or reproduction in other forums is permitted, provided the original author(s) and the copyright owner(s) are credited and that the original publication in this journal is cited, in accordance with accepted academic practice. No use, distribution or reproduction is permitted which does not comply with these terms. 